\title{
GEODERMA
}

Geoderma 97 (2000) 329-350

www.elsevier.nl/locate/geoderma

\section{Updating the $(1: 50,000)$ Dutch groundwater table class map by statistical methods: an analysis of quality versus cost}

\author{
P.A. Finke* \\ Alterra, P.O. Box 47, 6700AA, Wageningen, Netherlands
}

Received 1 September 1998; received in revised form 22 April 1999; received in revised form 4

August 1999; accepted 30 August 1999

\begin{abstract}
Groundwater table (GWT) class maps have been mapped for the whole of The Netherlands at a scale of 1:50,000, and provide useful information for a variety of purposes. Due to strong human impact on the Dutch landscape, water tables have changed and the maps now need updating. Six updating methods have been defined, varying in data requirements and in the smallest spatial unit that can be updated. The performance and cost of each of the methods were measured in a 9228-ha test area. The costs were also extrapolated to larger areas of 46,994 and 75,684 ha using measures of sampling error as criteria. The major cost factor is largely determined by the sample size, which is method dependent. A method that updates GWT maps by evaluating an objective function in locations obtained through stratified random sampling showed the best performance in the test area and a reasonable cost development at larger areas. Validation in the 75,684 ha area supported this conclusion. A kriging-based method performed well, but was expensive. In the near future, elevation data will be available at the national scale. Using these data as ancillary information will decrease cost and increase the accuracy of GWT map updates. This will allow for drawing new map polygons instead of re-labeling existing ones. (C) 2000 Elsevier Science B.V. All rights reserved.
\end{abstract}

Keywords: Water tables; Maps; Geostatistics; Probability sampling; Accuracy; Cost

\footnotetext{
* Fax: +31-7-424-812.

E-mail address: p.a.finke@alterra.wag-ur.nl (P.A. Finke).
}

0016-7061/00/\$ - see front matter (C) 2000 Elsevier Science B.V. All rights reserved.

PII: S0016-7061(00)00044-6 


\section{Introduction}

Groundwater table (GWT) class maps are used extensively in The Netherlands to estimate land capabilities and diverse land qualities (Haans et al., 1984). Also, these maps are essential to many studies in which water movement is calculated, either to provide boundary conditions for hydrological models (e.g., Finke et al., 1996) or to validate model results (Boers et al., 1997). A GWT class is defined by a typical combination of a class of mean highest (MHW) and a class of mean lowest (MLW) groundwater tables (Fig. 1). The MHW is defined as the mean value over 8 or more consecutive years of the three shallowest groundwater levels measured within each year, where the measuring frequency is biweekly. The MLW is defined likewise with the deepest groundwater levels. GTW maps are the only data source describing seasonal dynamics of phreatic water levels with national coverage. GWT classes have been surveyed in conjunction with the soil type between 1961 and 1992. The sampling density and the delineation of map polygons were such that maps with a presentation scale 1:50,000 could be drawn. Average sampling density was approximately 1 augering per 6 ha, which is the area of the smallest polygon that can be represented on these maps. Currently, scale is often defined in terms of extent and grain since digitisation of maps technically allows for presentation

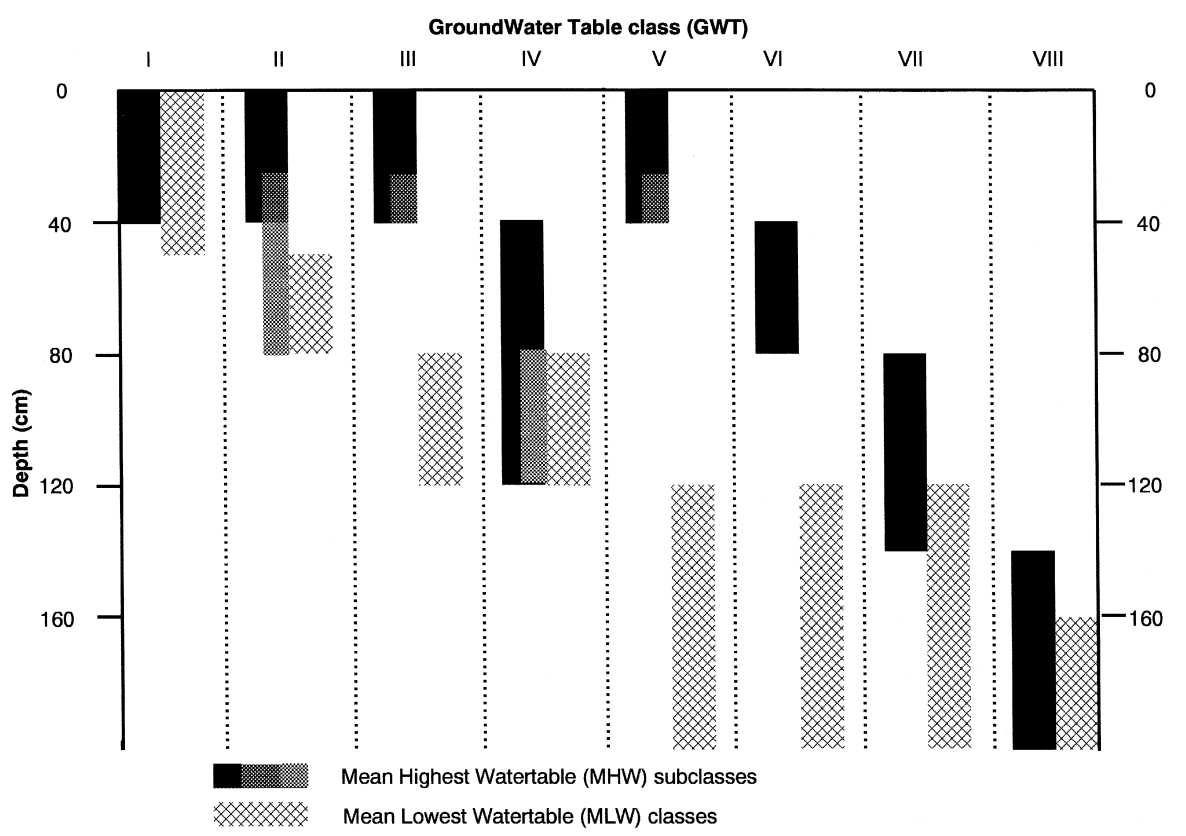

Fig. 1. Major GWT-classes as defined by MLW and MHW-classes. Subclasses of GWT follow from subclasses of MHW. 
at any level of detail (Dumanski et al., 1993). For the maps considered, the extent is given by the map boundaries, but the grain is not so easy to define. In fact there are two grains as far as the survey is considered: the grain which is used to delineate map polygons from geomorphological and pedological features and minimally has a support of a few hectares, and the point support grain which is used to (i) characterise the polygons in terms of MLW, MHW and GWT and (ii) to estimate within-polygon variability of these parameters.

The impact of humans on the Dutch landscape has affected the seasonal dynamics of the groundwater table fluctuations by activities such as land reclamation, drainage, re-allotment, levelling and groundwater extraction. These practices have led to a lowering of the groundwater tables in large parts of The Netherlands (Braat et al., 1989) and subsequently, this alteration of the GWT caused detoriation of GWT maps. Therefore, updating the GWT maps has become a major activity in the Dutch soil data acquisition programme. Since resources are inadequate to redo the mapping, alternative fast and cost-efficient methods are needed to update the existing map polygon attributes. Furthermore, available data, funds and desired accuracy of the updated maps are known to vary by region, so multiple updating methods may be required. The current study focuses on the development of several methods to update GWT maps, the analysis of the accuracy of resulting maps, and the associated costs for different regions. This paper deals with four issues: The (i) definition of six updating methods by a data requirement, a sampling requirement and an updating algorithm; (ii) application of each of these methods in a test area of 9228 ha, quantifying the associated cost and the map accuracy; (iii) extrapolation of the cost of each updating method to larger areas; (iv) validation of one method in a large area of 75,684 ha.

\section{Material and methods}

\subsection{Data and methods}

\subsubsection{Primary data sources and field data acquisition}

For the updating methods to be applicable irrespective of the region, it is necessary that some minimal data requirements be satisfied. First, it is necessary to have time series of phreatic heads that minimally cover the 8 most recent years, otherwise MLW and MHW cannot be estimated. An existing long-term, monitoring network of piezometers with national coverage satisfies this requirement. Second, it is necessary to have information on the spatial extent of hydrological systems, groundwater extraction zones and zones otherwise strongly influenced by human activity. This information, combined with the existing 
GWT maps, may be used to define sampling strata since the ageing rate of the GWT maps is assumed to vary with these strata. Since the polygons on the GWT map were drawn on the basis of geomorphological and pedological criteria, these criteria are implicitly part of the stratification. For the methods to be applicable to other areas, national coverage of the data used to stratify should exist as well. For hydrological zones, the ecohydrological districts from Braat et al. (1989) are used, which are defined by (i) hydrological (sub-) system such as infiltration or exfiltration area, catchment delineation and characteristic drainage pattern; and (ii) floristic composition resulting from groundwater quality and parent material. To delineate groundwater extraction areas, the zones can be used in which phreatic water moves to the extraction well in less than 10 years. For the major extractions, these zones are estimated by model studies.

The density of the national phreatic head monitoring network roughly varies between one suitable permanent piezometer per 750 to 1250 ha. For some updating methods, this density is too low (c.f. Section 2.1.4), and additional MLW/MHW observations need to be made. Te Riele and Brus (1991) gave a method for estimating the MHW from well-timed phreatic head measurements in temporary piezometers. First, the phreatic head is measured at the same date in both the permanent piezometers of the network and in temporary piezometers. The date is chosen carefully to ascertain that groundwater levels are near MHW (or MLW). Second, a regression relation is fitted between the MHW and the head in the permanent piezometers for this date, or, possibly, for more than one date. Third, this relation is applied to the heads in the temporary piezometers, resulting in an estimate of the MHW. The accuracy of the relation is usually best after a brief dry period in a wet part of the winter, but the accuracy of the regression relation itself can be monitored to choose the best time to measure the temporary piezometers. The same procedure can be followed in a dry summer situation to estimate the MLW. A typical accuracy of MLW and MHW in terms of the square root of the residual variance of the regression model is between 10 and $15 \mathrm{~cm}$ (Te Riele and Brus, 1991).

\subsubsection{Test areas}

The GWT map updating methods were applied to an area of 9228 ha in the Eastern part of the Netherlands (Fig. 2). This area is characterised by the Holocene IJssel river valley in the western part and an area with Pleistocene coversands in the eastern part of the area. In between, high coversand ridges and valleys occur. These three areas, each coinciding with an ecohydrological district, have clearly different drainage patterns and surface topography.

The costs of the updating methods were measured for the area, and were also extrapolated to larger areas of 46,994 ha in the same region (map sheet 27 East) and of 75,684 ha in the North-eastern part of the Netherlands (Province of Drenthe). This largest area was updated in a separate project. Table 1 gives some information on the number of GWT map units, the number of ecohydro- 


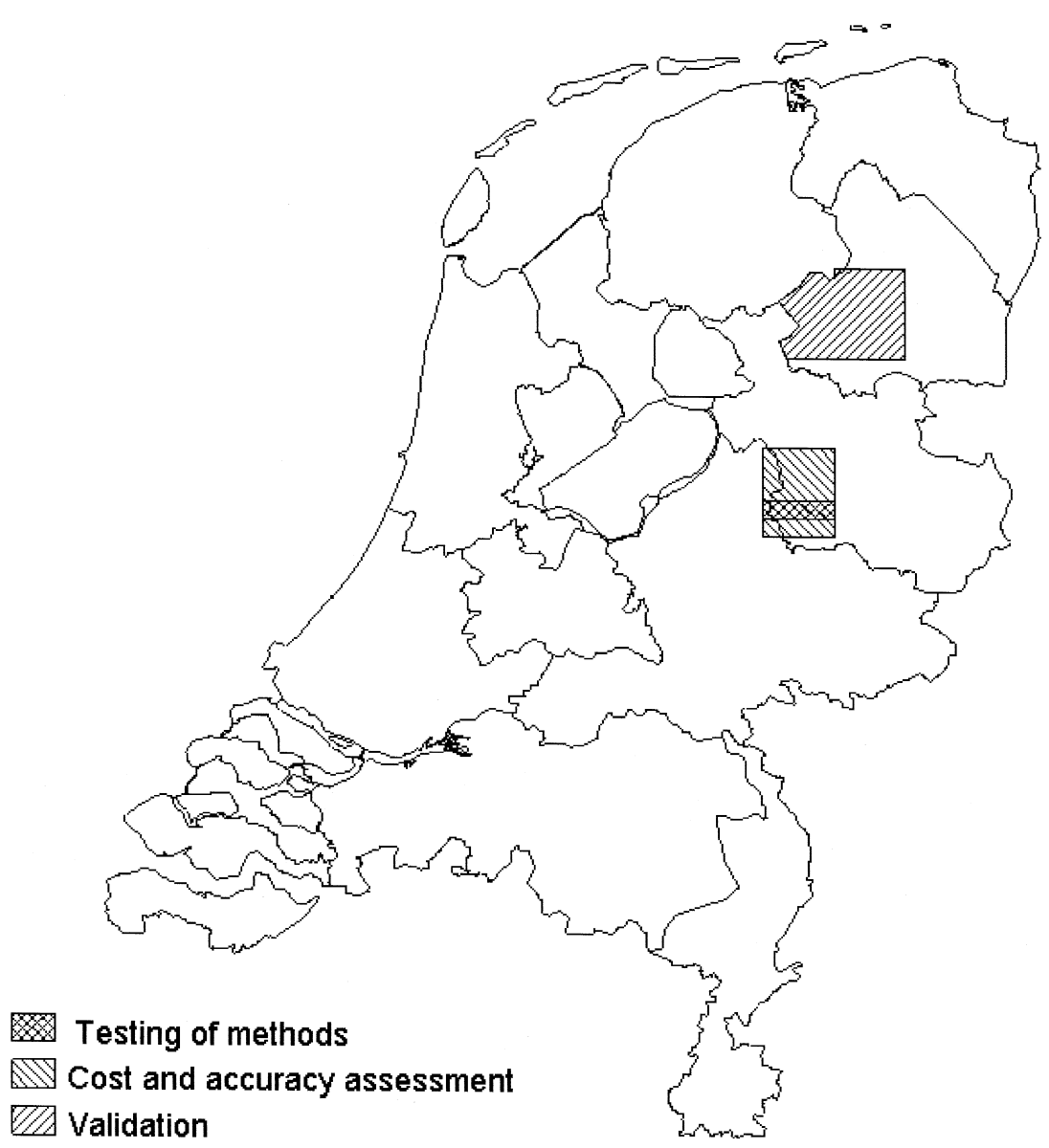

Fig. 2. Research areas.

logical districts and the number of zones with strong human influence in each of these areas.

\subsubsection{An objective function for map accuracy}

The GWT is a composite, ordinal variable based on classes of MHW and MLW (Bregt et al., 1992a,b). To estimate the accuracy of a GWT map, the map

Table 1

Some properties of the research areas

\begin{tabular}{rlllc}
\hline Area (ha) & $\begin{array}{l}\text { GWT map } \\
\text { units }\end{array}$ & $\begin{array}{l}\text { Ecohydrological } \\
\text { districts }\end{array}$ & $\begin{array}{l}\text { Zones of strong } \\
\text { human influence }\end{array}$ & $\begin{array}{l}\text { Sampling } \\
\text { strata }\end{array}$ \\
\hline 9228 & 19 & 3 & 3 & 47 \\
46,994 & 22 & 5 & 4 & 90 \\
75,684 & 16 & 10 & 5 & 111 \\
\hline
\end{tabular}


purity (Beckett and Webster, 1971) could be used, which is the area fraction of a map unit in which the mapped property corresponds to the map unit definition. In this case, a point observation would either correspond to the definition or not. Since at the point scale MHW and MLW can be estimated quantitatively, the degree of non-correspondence of both variables to the definition by GWT can be used as a measure of accuracy at the point scale. An objective function $G$ is therefore defined as:

$$
G(i)=G_{\mathrm{MLW}}(i)+G_{\mathrm{MHW}}(i)
$$

where:

$$
G_{\mathrm{MLW}}(i)=\left\{\begin{array}{cl}
0 & \text { if MLW within definition } \\
\operatorname{ABS}\left(\frac{\operatorname{MLW}_{\mathrm{GWT}, \mathrm{ncb}}(i)-\operatorname{MLW}(i)}{\mathrm{MLW}_{\mathrm{GWT}, \mathrm{ncb}}(i)}\right) & \text { if MLW outside definition }
\end{array}\right.
$$

and $\operatorname{MLW}(i)$ is the Mean Lowest Water table at location $i[\mathrm{~L}]$ and $\operatorname{MLW}_{\mathrm{GWT}, \text { ncb }}(i)$ is the nearest boundary of the MLW class corresponding with the GWT at location $i$ [L]. The smallest value of $\operatorname{MLW}_{\mathrm{GWT}, \mathrm{ncb}}(i)$ entered in the above equation is $1 \mathrm{~cm}$. $G_{\mathrm{MLW}}$ thus expresses the degree to which the map is impure at location $i$ for the MLW. The denominator $\operatorname{MLW}_{\mathrm{GWT}, \mathrm{ncb}}(i)$ gives more emphasis to differences from the GWT definition in situations with shallow water tables, because a 5-cm difference under wet circumstances is considered more important for processes in the topsoil than under dry circumstances. Examples are the sensitivity of the denitrification rate and of wetland vegetations to small differences in shallow water tables. $G_{\mathrm{MHW}}$ is calculated the same way.

At the regional extent, the average map accuracy (MG) is then calculated from $G$ values at $n$ locations by:

$$
\mathrm{MG}=\sum_{i=1}^{n} g_{i} G_{i}
$$

where $g_{i}$ is the weight assigned to a point value of $G$, depending on the sampling design, and all weights $g_{i}$ sum up to 1 . In case of simple random sampling, $g_{i}$ would always equal to $1 / n$.

Furthermore, the percentage of the area where the map GWT strongly deviates from point values of MLW and MHW is defined by:

$$
\mathrm{FEXG}=100 \sum_{i=1}^{n} g_{i} I_{i}
$$

with $I_{i}=1$ if $G_{i} \geq 1$ and $I_{i}=0$ if $G_{i}<1$.

\subsubsection{Methods for updating GWT maps}

The purpose of the study was to define and compare updating methods that are applicable in a range of situations with respect to available budget and data. 
It is well known (Bie and Beckett, 1971; Dent and Young, 1981, p. 97; Bregt et al., 1992a,b) that cost for soil mapping are largely determined by the number of labour days spent in the field. I postulate that this also holds true for map updating. So in order to cover a wide cost range, the methods should vary with the amount of fieldwork. Consequently, the methods must also differ in the smallest spatial unit that can be updated, since a spatial unit cannot be updated without data. A third criterion for the design of the methods was, that different ways to update the GWT of polygons were to be explored. Table 2 defines the methods developed in terms of data requirements and SSU. Below, each method is summarised in terms of data requirements, necessary sampling effort and the updating algorithm.

2.1.4.1. Straightforward update based on piezometer data (PS). The PS method only uses the existing GWT map polygons and data from the existing national phreatic head monitoring network. The update procedure is as follows:

(i) At the locations from the monitoring network, MLW and MHW are calculated from the time series of phreatic heads using biweekly data from the 8 most recent consecutive years.

(ii) The MLW and MHW point values are assigned to strata by their co-ordinates. A stratum is a set of map polygons with the same GWT on the existing map.

(iii) MLW values in each stratum are averaged, as are MHW values.

(iv) The GWT from the existing map is redefined by calculating a new GWT from the average MLW and MHW.

If the map unit on the existing GWT map is an association (i.e., in areas with significant topography within the minimal polygon size that can be represented at 1:50,000 scale), it cannot be assigned more than one GWT, and is assigned a single GWT.

2.1.4.2. Evaluation of alternative GWT based on piezometer data (PE). The PE method uses the same data as PS. The update procedure is as follows:

(i) At the locations from the monitoring network, MLW and MHW are calculated from the time series of phreatic heads using biweekly data from the 8 most recent consecutive years.

(ii) The MLW and MHW point values are assigned to strata by their co-ordinates. A stratum is a set of map polygons with the same GWT on the existing map.

(iii) The new GWT for each stratum is defined by an algorithm that selects the GWT with a minimal value of MG for the stratum, whereby MG is calculated using the point values of MLW and MHW within the stratum. 
Table 2

Data requirements and Smallest Spatial Unit (SSU) for each updating method

\begin{tabular}{|c|c|c|c|c|}
\hline \multirow[t]{2}{*}{ Method } & \multicolumn{3}{|l|}{ Data requirements } & \multirow[t]{2}{*}{ SSU } \\
\hline & $\begin{array}{l}\text { Piezometer time } \\
\text { series, GWT maps }\end{array}$ & $\begin{array}{l}\text { Maps of ecohydrological } \\
\text { districts and zones of } \\
\text { strong human influence }\end{array}$ & $\begin{array}{l}\text { Additional phreatic } \\
\text { head measurements }\end{array}$ & \\
\hline Piezometer straight PS & Yes & No & No & GWT-stratum \\
\hline Piezometer evaluated PE & Yes & No & No & GWT-stratum \\
\hline $\begin{array}{l}\text { Stratified random sampling } \\
\text { straight SRS-S }\end{array}$ & Yes & Yes & Yes & subset of GWT-stratum ${ }^{a}$ \\
\hline $\begin{array}{l}\text { Stratified random sampling } \\
\text { evaluated SRS-E }\end{array}$ & Yes & Yes & Yes & subset of GWT-stratum ${ }^{a}$ \\
\hline Polygonwise POL & Yes & No & Yes & GWT-Polygon \\
\hline Modal kriging estimate MKE & Yes & No & Yes & GWT-Polygon \\
\hline
\end{tabular}

${ }^{\text {a }}$ Substratification based on ecohydrological districts and zones of strong human influence. 
If the existing GWT map unit is an association, possible associations are evaluated as well to find the minimal MG.

2.1.4.3. Straightforward update with data from a stratified random sampling design (SRS-S). The SRS-S method also uses the MLW and MHW data from the monitoring network, but differs from PS in that it involves fieldwork. Fieldwork consists of taking phreatic head measurements at well-chosen points in time (cf. Section 2.1.1) and at randomly chosen locations. Hereto,

(i) unique combinations of map units of the existing GWT map, the map with ecohydrological districts and the map with zones of strong human influence are defined to serve as sampling strata. Each one of these strata is sampled according to a random sampling design, whereby three random locations per stratum are visited at three points in time.

(ii) the well-timed phreatic head measurements are translated to MLW and MHW using the data from the monitoring network and the regression method described in Section 2.1.1.

(iii) for each stratum, the average MLW and MHW determine a new GWT.

If the map unit on the existing GWT map is an association, it cannot be assigned more than one GWT, and is assigned a single GWT.

2.1.4.4. Evaluation of alternative GWT with data from a stratified random sampling design (SRS-E). The SRS-E method follows the same approach as SRS-S (step i and ii), only the new GWT is defined differently (below).

(iii) The new GWT for each stratum is defined by an algorithm that selects the GWT with a minimal value of MG for the stratum, whereby $M G$ is calculated using the point values of MLW and MHW within the stratum.

If the existing GWT map unit is an association, possible associations are evaluated as well to find the minimal MG. Furthermore, GWT associations are checked in the field by an experienced surveyor as well.

2.1.4.5. Polygonwise update data from one randomly selected location per 500 $h a(P O L)$. The POL method uses the MLW and MHW data from the monitoring network and involves some fieldwork as well. The update method is:

(i) Each map polygon is sampled according to a random sampling design, whereby one random location per map polygon or per 500 ha within a map polygon (whichever has the smallest area) is visited at three points in time. (ii) The well-timed phreatic head measurements at the random points are translated to MLW and MHW using the data from the monitoring network and the regression method described in Section 2.1.1. 
(iii) For each polygon, a new GWT is determined from the MLW and MHW or their average values.

2.1.4.6. Polygonwise update with the modal kriging estimate (MKE). The MKE method uses the MLW and MHW data from the monitoring network and involves some fieldwork as well. The method is based on a model of spatial variation, namely that a spatial trend exists and the residuals of MHW and MLW to the local trend surface are autocorrelated. Kriging in the presence of trend is used to obtain more MLW and MHW values in each polygon from the field data. Previous research in the Netherlands has shown, that at regional extent, a trend may occur in phreatic heads (Stolp et al., 1994). The calculation for the new GWT for each polygon is given below (step i and ii are the same as in the method POL).

(iii) From all MHW and MLW point data, the trend and parameters of generalised covariance models for MLW and MHW are estimated, following the restricted maximum likelihood method by Kitanidis (1983);

(iv) For each GWT polygon, MLW and MHW are predicted at 100 random locations, with IRF $k$ kriging (Kafritsas and Bras, 1981). It was chosen to do multiple interpolations and classification into GWT classes at random locations and then choosing the modal class instead of straightforward block kriging. The latter would yield an average MLW and MHW and GWT that are quite different from modal GWT in case of bimodally distributed MLW or MHW (which is possible when polygon boundaries are mislocated). Also, since GWT is a nonlinear function of MLW and MHW, a GWT based on averaged MLW and MHW is not necessarily equal to the modal GWT.

(v) The new GWT for the polygon is the most frequent (modal) GWT at the 100 locations.

If the polygon on the existing GWT map is an association, a new association is defined by a combination of the single GWTs that together occur at least at 70 locations $(70 \%$ is the target map purity for any soil/GWT map 1:50,000 in the Netherlands).

\subsection{Extrapolation of costs to larger areas}

\subsubsection{Cost components}

The cost of a GWT map update can be divided into three types and eight components (Table 3). The three types involve fixed costs and two types of variable costs. The fixed costs have to be made for any type of updating method, such as map production and reporting. These costs can be estimated on experience. Some variable costs depend on the acreage but not on the method. An example is the field check of the available piezometers. In a larger area, the 
Table 3

Main cost components for each updating method. Update methods are explained in text. $F=$ fixed cost; $V(A)=$ Variable function of area; $V(A, \mathrm{M})=$ Variable function of area and method; $-=$ not applicable

\begin{tabular}{lllllll}
\hline Cost component & \multicolumn{7}{l}{ Update method } \\
\cline { 2 - 7 } & PS & PE & SRS-S & SRS-E & POL & MKE \\
\hline$\left(V_{1}\right)$ Selection useable permanent & $V(A)$ & $V(A)$ & $V(A)$ & $V(A)$ & $V(A)$ & $V(A)$ \\
piezometers & & & & & & \\
$\left(V_{2}\right)$ Fieldcheck permanent piezometers & $V(A)$ & $V(A)$ & $V(A)$ & $V(A)$ & $V(A)$ & $V(A)$ \\
$\left(V_{3}\right)$ Sampling design and preparation & - & - & $V(A, \mathrm{M})$ & $V(A, \mathrm{M})$ & $V(A, \mathrm{M})$ & $V(A, \mathrm{M})$ \\
of field work (making of field maps, & & & & & & \\
asking permission to land owners) & & & & & & \\
$\left(V_{4}\right)$ Fieldwork: three phreatic head & - & - & $V(A, \mathrm{M})$ & $V(A, \mathrm{M})$ & $V(A, \mathrm{M})$ & $V(A, \mathrm{M})$ \\
measurements & & & & & & \\
$\left(F_{1}\right)$ Translation field measurements & - & - & $F$ & $F$ & $F$ & $F$ \\
to MLW and MHW & & & & & & \\
$\left(F_{2}\right)$ Update of GWT map & $F$ & $F$ & $F$ & $F$ & $F$ & $F$ \\
$\left(V_{5}\right)$ Fieldcheck GWT-associations & - & - & - & $V(A)$ & - & - \\
$\left(F_{3}\right)$ Reporting and map production & $F$ & $F$ & $F$ & $F$ & $F$ & $F$ \\
\hline
\end{tabular}

number of available piezometers usually is larger as well. Other variable costs depend on both the acreage and the updating method. For example, the increase of the number of observations with increasing acreage is method dependent. The eight cost components in Table 3 are estimated as follows (variables in italics):

$$
\begin{array}{rlrl}
V_{1} & =N_{\text {mapsheets }} \cdot 0.9 \frac{\mathrm{kEuro}}{\text { mapsheet }} & & \text { (data extraction) } \\
V_{2} & =\frac{N_{\text {mapsheets }}}{0.25 \text { mapsheets } / \text { day }} \cdot 0.5 \frac{\mathrm{kEuro}}{\mathrm{day}} & & N_{\text {sample points }} \\
V_{3} & =\left(\frac{\mathrm{ha}}{25000 \mathrm{ha} / \text { day }}+\frac{\mathrm{kEuro}}{15 \text { sample points } / \text { day }}\right) \cdot 0.5 \frac{\text { (field check piezometers) }}{\text { day }} & & \text { (sampling design }+ \\
\text { asking permission to } & \text { landowners) } \\
V_{4} & =\frac{N_{\text {sample point }} \cdot 3 \text { visits }}{15 \text { sample points } / \text { day }} \cdot 0.5 \frac{\mathrm{kEuro}}{\text { day }} & & \text { (3 well-timed phreatic } \\
V_{5} & =\frac{N_{G W T-\text { association polygons }}}{5 \text { polygons } / \text { day }} \cdot 0.5 \frac{\mathrm{kEuro}}{\text { day }} & & \text { measurements) } \\
F_{1} & =0.9 \mathrm{kEuro} & & \text { (field check GWT-asso- } \\
F_{2} & =0.9 \mathrm{kEuro} & & \text { ciations) } \\
F_{3} & =5.9 \mathrm{kEuro} & & \begin{array}{l}
\text { (data interpretation) } \\
\text { (map update) }
\end{array}
\end{array}
$$

The cost components depending on both methods and acreage are dominated by the amount of fieldwork, and are directly related to the sample size of the 
phreatic measurements. Extrapolation of cost assessments to larger areas should therefore be based on correct estimates of sample sizes in these areas.

\subsubsection{Sample sizes in larger areas}

The estimation of the sample size for larger areas starts from the proposition that the accuracy of the updated GWT map in the larger area should be equal to that in the 9228-ha test area, and that this accuracy is directly related to sampling design and sample size. For each updating method that requires additional fieldwork (SRS-S, SRS-E, POL and MKE) this proposition is translated to a quantifiable sampling requirement.

2.2.2.1. $S R S-S$ and $S R S-E$. The sampling requirement is defined as follows: the standard deviation of the estimation error of MLW and MHW in larger areas should equal that in the test area under the same sampling design. Domburg et al. (1994) defined a method to predict the sampling error for stratified random sampling designs such as in this study, based on the variogram of MLW (MHW), the stratification of the area and the delineation of the GWT polygons. The variograms of MLW and MHW in the 9228-ha test area were used for the larger areas as well, and the other data were taken from available digital GWT maps, ecohydrological districts and zones influenced by human activity. Following Domburg et al. (1994), the method to predict the sampling error for different areas in case of a stratified random design consists of three steps:

(i) Using the stratification, the location and delineation of the GWT polygons within each stratum and the variogram, the average semivariance is estimated within each stratum. This estimation was based on 50 couples from 100 randomly selected locations within each stratum.

(ii) For each stratum, the relative area is calculated.

(iii) In case of simple random sampling within the strata, the predicted sampling error is then calculated by (Domburg et al., 1994):

$$
\hat{\vec{r}}=\sqrt{\sum_{h \simeq 1}^{L} \frac{w_{h}^{2}}{n_{h}} \bar{\gamma}_{A_{h}, A_{h}}}
$$

where $\hat{\bar{r}}$ is the predicted area-weighted sampling error $(\mathrm{cm}), L$ is the number of strata, $w_{h}$ is the relative area of stratum $h, \bar{\gamma}_{A_{h, \mathrm{~A}}}$ is the average semivariance in area $A$ within stratum $h$ and $n_{h}$ is the number of observations within stratum $h$.

In the test area, $n_{h}$ equalled 3 for each one of 47 strata, which is known to be less efficient as proportional allocation whereby $n_{h}$ depends on the acreage of the stratum $h$ (Brus, 1994). I, therefore, reallocated the 141 sample points proportionally with a minimum of two per stratum, and recalculated the 
sampling error for MLW and MHW. These sampling errors were used as accuracy criteria for samplings in the larger areas.

2.2.2.2. POL. The sample size in larger areas is directly related to the number of GWT polygons, whereby extra observations are added if polygons are larger than 500 ha. This calculation is a straightforward GIS operation, and involves (i) counting the number of polygons smaller than 500 ha $\left(n_{1}\right)$; and (ii) counting the area $A$ of each polygon larger than 500 ha and calculating $n_{2}=1+A \operatorname{div} 500$ (div is the integer division operator); and (iii) adding $n_{1}$ to $n_{2}$ to obtain the sample size.

2.2.2.3. MKE. The sampling requirement is defined as follows: the square root of the average prediction error variance $(\mathrm{R} \overline{\mathrm{PEV}})$ in a larger area should be equal to that in the 9228 -ha test area. $\mathrm{R} \overline{\mathrm{PEV}}$ is calculated from kriging prediction error variances $\mathrm{PEV}$ as follows:

(i) in each polygon 100 kriging interpolations are performed as in the updating method;

(ii) the average PEV per polygon is calculated from

$$
\overline{\mathrm{PEV}}_{\mathrm{pol}}=\frac{1}{100} \sum_{i=1}^{100} \mathrm{PEV}_{i, \mathrm{pol}}
$$

(iii) which is then aggregated to an areal average by weighing by the relative area $A_{\mathrm{pol}} / A$ of the polygons:

$$
\overline{\mathrm{PEV}}=\sum_{\mathrm{pol}=1}^{m}\left(\frac{A_{\mathrm{pol}}}{A} \overline{\mathrm{PEV}}_{\mathrm{pol}}\right)
$$

Two sample allocation variants were analysed: (i) the variant actually carried out in the test area, whereby one sample location is randomly allocated within each polygon smaller than 500 ha and one random location is added for each 500 ha more; (ii) a variant that ignores the existing GWT map polygons and uses simple random sampling.

\subsection{Validation}

\subsubsection{Accuracy test in research area}

The accuracy assessment of the GWT maps resulting from each map updating method should be based on an independent test set of MLW/MHW values. Therefore, 60 independent test point values were obtained after stratified random sampling with the ecohydrological districts as strata. The MG and FEXG were calculated to quantify map accuracy. 


\subsubsection{Cost and accuracy in Drenthe project}

The 75,684 ha area in the Province of Drenthe was actually updated one year after the comparative study on updating methods. This updating was based on a large number of MLW and MHW values and used method SRS-E. To enable validation of both cost and accuracy of SRS-E, a subsample was taken from the available data set, such that the remaining sample size was equal to the predicted necessary sample size for this area, while maintaining a proportional stratified random sampling design. The costs were post-calculated after the project finished, with a correction for the reduced sample size. The accuracy of the new map, updated with the subsample, was estimated by calculating the MG, using an independent dataset of 60 test points.

\section{Results}

\subsection{Accuracy of updated maps}

The accuracy test (Table 4) shows clear differences between the methods. The methods using only piezometer data (PS and PE) hardly improve the existing map. Due to lack of data, some GWT map units cannot be updated by these methods ( $7 \%$ of the area). Additionally, the resulting maps do not carry much information, since the number of GWT map units strongly decreases from 19 (existing map) to 4 (PS) or 5 (PE). The methods based on stratified random sampling have a good overall accuracy (MG 0.18 or 0.12 ), and the resulting GWT maps are almost always in agreement with point data of MLW and MHW (FEXG of $0.5 \%$ of the area). The method that updates polygons directly from point data does perform less well, as shown by much higher MG and FEXG values. The MKE method results in maps with a low MG and an intermediate FEXG value.

Table 4

Accuracy parameters and properties of updated maps following different methods in the 9228-ha test area. The heterogeneity conservation is defined as the number of GWT map units relative to that of the existing map. n.r. = not relevant

\begin{tabular}{lllll}
\hline Method & $\begin{array}{l}\text { Updated } \\
\text { area }(\%)\end{array}$ & $\begin{array}{l}\text { Heterogeneity } \\
\text { conservation }(-)\end{array}$ & FEXG $(\%)$ & MG $(\mathrm{cm} / \mathrm{cm})$ \\
\hline Existing map & n.r. & 1 & 7.4 & 0.27 \\
PS & 93 & 0.2 & 7.3 & 0.22 \\
PE & 93 & 0.3 & 7.3 & 0.22 \\
SRS-S & 100 & 0.4 & 0.5 & 0.18 \\
SRS-E & 100 & 0.6 & 0.5 & 0.12 \\
POL & 100 & 0.4 & 6.3 & 0.20 \\
MKE & 100 & 0.5 & 3.7 & 0.16 \\
\hline
\end{tabular}




\subsection{Cost assessment at areas of different size}

\subsubsection{Sample sizes}

3.2.1.1. SRS-S and SRS-E. Fig. 3 shows how the sample size relates to the predicted sampling error for both proportional and equal sampling in the three

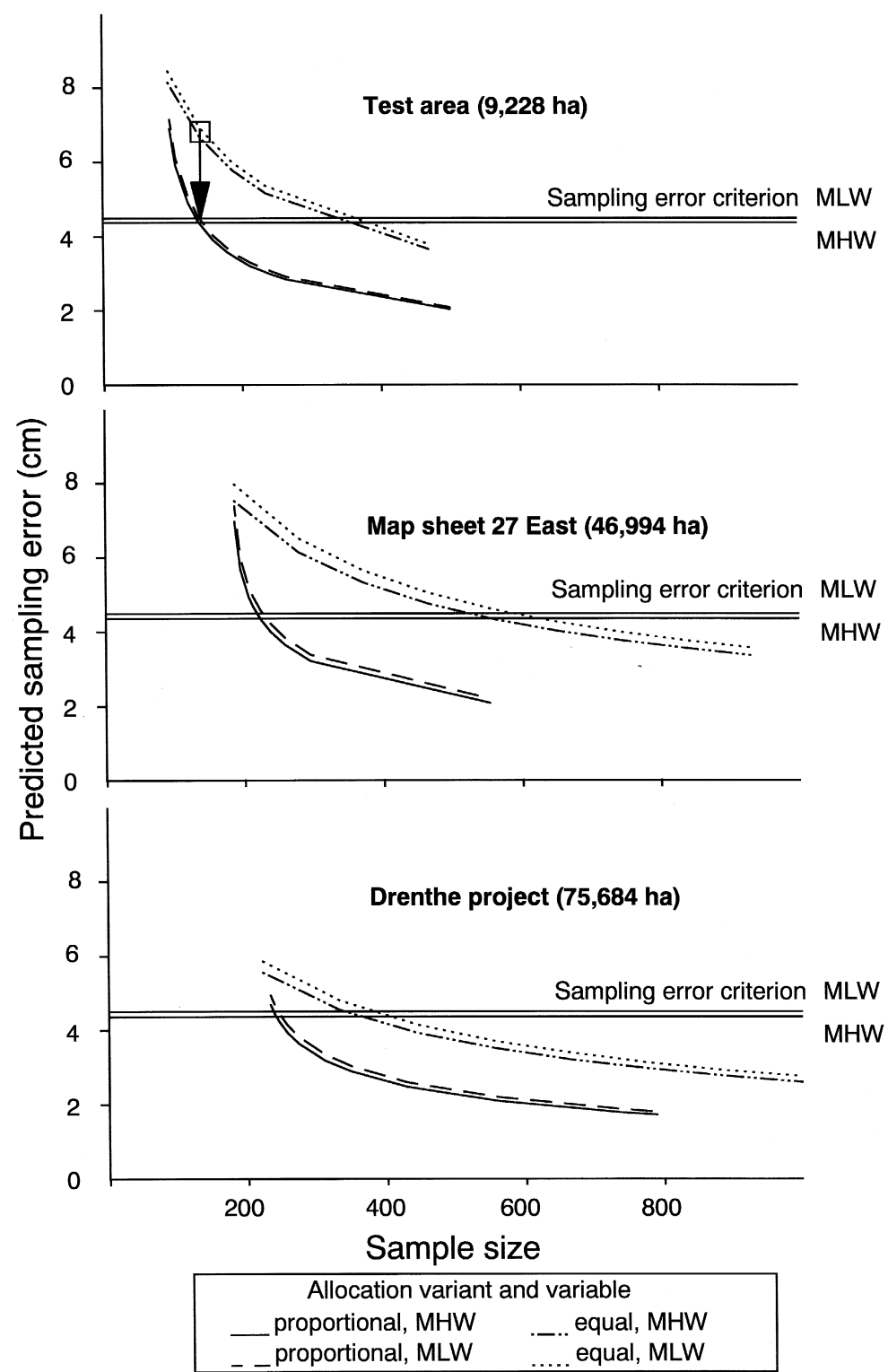

Fig. 3. Predicted sampling error as function of sample size for proportional and equal stratified random sampling for three areas. 
Table 5

Parameter values of variograms fitted to 174 sample points with MLW and MHW data in the test area

\begin{tabular}{llllc}
\hline Variable & Best fitted model & Nugget $\left(\mathrm{cm}^{2}\right)$ & Sill $\left(\mathrm{cm}^{2}\right)$ & Range $(\mathrm{m})$ \\
\hline MHW & exponential & 120 & 2470 & 626 \\
MLW & exponential & 320 & 2830 & 1080 \\
\hline
\end{tabular}

areas. Fig. 3 was based on the variograms for MLW and MHW in the test area (Table 5), and on the stratification by GWT polygons, ecohydrological districts and zones of human influence in all three areas. In all cases, proportional sampling is more favourable because sampling errors are less at the same sample sizes. The upper part of the figure shows how the actual situation in the test area (three random samples per stratum) was converted to sampling error criteria for MLW $(4.4 \mathrm{~cm})$ and MHW $(4.5 \mathrm{~cm})$ based on proportional sampling. These criteria can be met in map sheet 27 East at $n=227$, and in the Drenthe project at $n=246$.

3.2.1.2. POL and MKE. With the POL method, the sample size increases from 174 (test area) to 633 (map sheet 27 East) to 1122 (Drenthe project). The development of sample size for the MKE method is shown in Fig. 4. Allocating

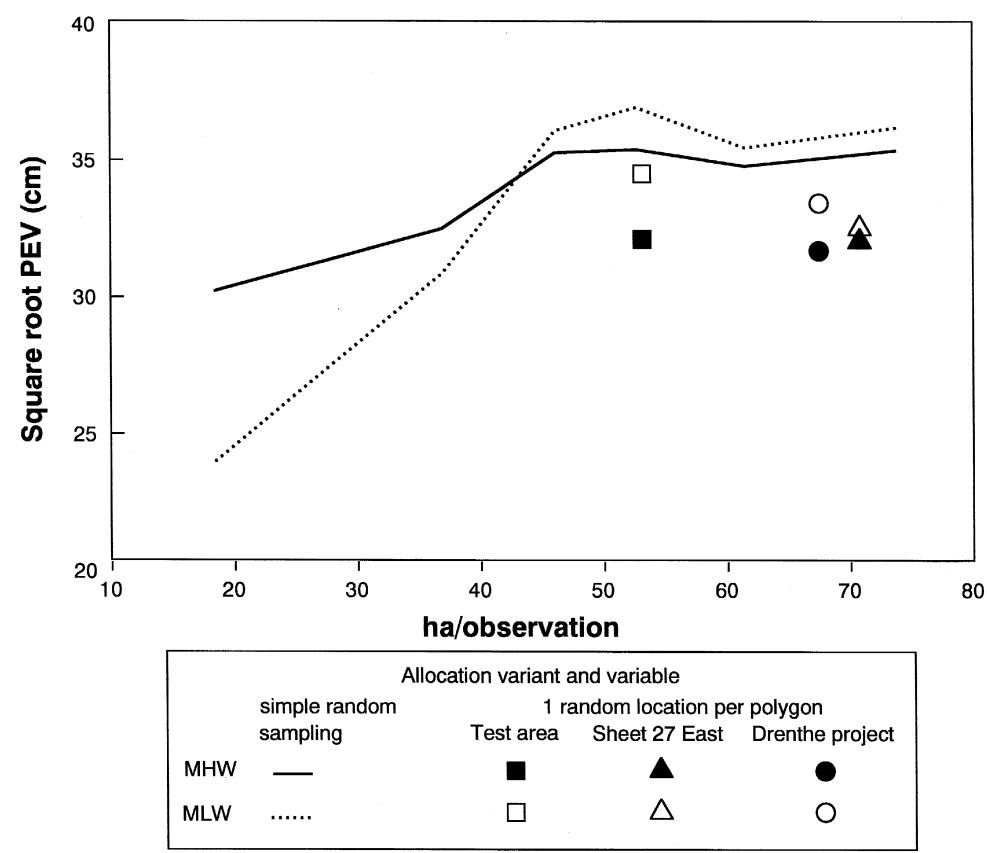

Fig. 4. Square root of prediction error variance as a function of sampling density for simple random sampling and polygonwise sampling for three areas. 
one random sample location for each polygon leads to lower values for RPEV than the same sample size with simple random sampling. Also, it appears that the RPEV varies little between the three areas in case of polygonwise sampling. For these reasons, the cost calculations for the MKE method are based on polygonwise samplings, with the same sample sizes as the POL method. These sampling densities (50-70 ha/observations) correspond to average distances between observations from 700 to $840 \mathrm{~m}$, which is close to or beyond the "range" parameter of the fitted variograms (Table 5).

\subsubsection{Cost estimates}

The relation between total cost, size of the area to be updated and updating method is shown in Fig. 5. The cost associated with piezometer updating methods are by far lowest and do hardly increase by area because little fieldwork is required. Differences in the evolution of total costs with increasing area between SRS methods, POL and MKE are related to differences in sample size.

\subsection{Marginal costs}

The marginal costs are here defined as the ratio of the investment (the total costs) over the accuracy improvement $\left(\mathrm{MG}_{\text {before update }}-\mathrm{MG}_{\text {after update }}\right)$ due to the

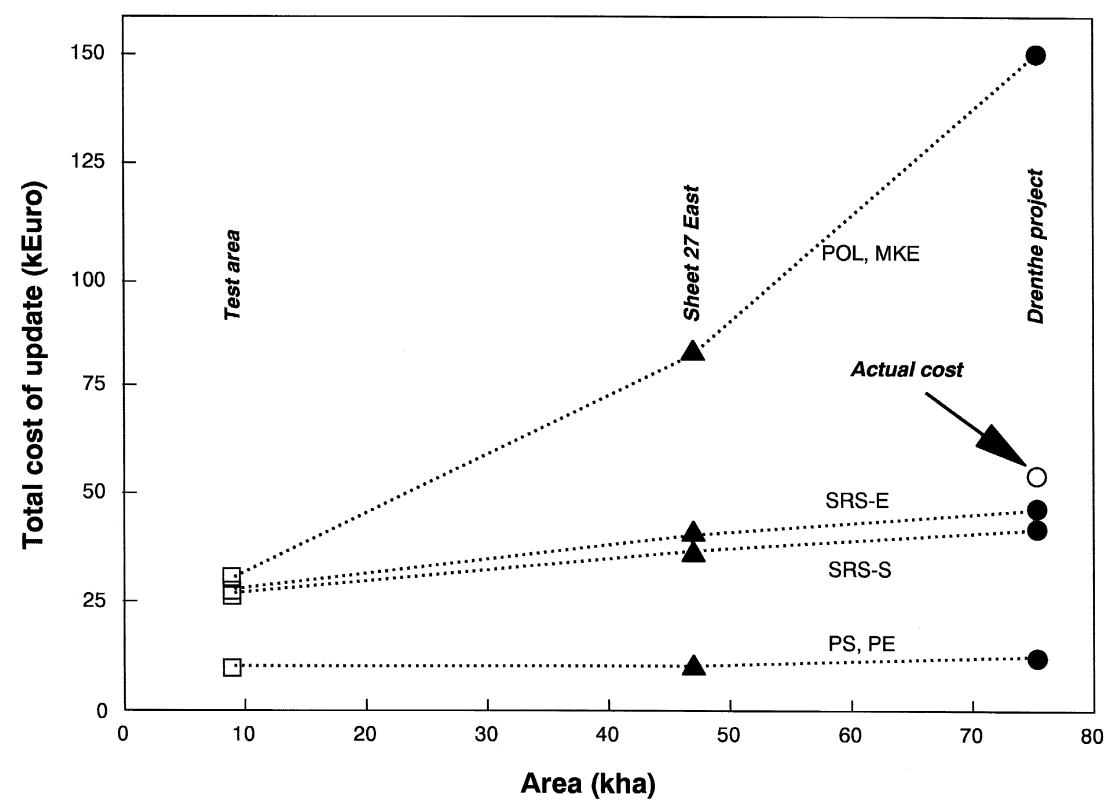

Fig. 5. Total cost for three areas as a function of the updating method. Open markers are measured cost, closed markers indicate results from the extrapolation, the open circle indicates the actual cost made in the Drenthe project. 
Table 6

Accuracy, cost and marginal cost $\left(\mathrm{Cost} /\left(\mathrm{MG}_{\text {before }}-\mathrm{MG}_{\text {after }}\right)\right)$ in the three research areas. Underlined numbers result from the validation in the Drenthe project

\begin{tabular}{|c|c|c|c|c|c|c|c|c|c|c|}
\hline \multirow[t]{2}{*}{ Method } & \multirow{2}{*}{$\begin{array}{l}\text { Assumed MG } \\
\text { after update }\end{array}$} & \multicolumn{3}{|l|}{ Test area } & \multicolumn{3}{|c|}{ Map sheet 27 East } & \multicolumn{3}{|c|}{ Drenthe project } \\
\hline & & $\begin{array}{l}\text { MG before } \\
\text { update }(-)\end{array}$ & $\begin{array}{l}\text { Cost } \\
\text { (kEuro) }\end{array}$ & $\begin{array}{l}\text { Marginal } \\
\text { cost (kEuro) }\end{array}$ & $\begin{array}{l}\text { MG before } \\
\text { update }(-)\end{array}$ & $\begin{array}{l}\text { Cost } \\
\text { (kEuro) }\end{array}$ & $\begin{array}{l}\text { Marginal } \\
\text { cost (kEuro) }\end{array}$ & $\begin{array}{l}\text { MG before } \\
\text { update }(-)\end{array}$ & $\begin{array}{l}\text { Cost } \\
\text { (kEuro) }\end{array}$ & $\begin{array}{l}\text { Marginal } \\
\text { cost (kEuro) }\end{array}$ \\
\hline$\overline{\mathrm{PS}}$ & 0.22 & 0.27 & 10 & 200 & 0.40 & 10 & 56 & 1.58 & 12 & 9 \\
\hline $\mathrm{PE}$ & 0.22 & 0.27 & 10 & 200 & & 10 & 56 & 1.58 & 12 & 9 \\
\hline SRS-S & 0.18 & 0.27 & 27 & 298 & & 36 & 165 & 1.58 & 41 & 30 \\
\hline SRS-E & $0.12, \underline{0.32}$ & 0.27 & 28 & 185 & & 40 & 143 & 1.58 & $46, \underline{54}$ & $31, \underline{43}$ \\
\hline POL & 0.20 & 0.27 & 30 & 429 & & 81 & 405 & 1.58 & 151 & 109 \\
\hline MKE & 0.16 & 0.27 & 31 & 277 & & 81 & 339 & 1.58 & 151 & 106 \\
\hline
\end{tabular}


application of the updating method. To be able to estimate the marginal cost, the accuracy of the existing maps of map sheet 27 East and the Drenthe project had to be estimated in terms of their MG value. The MG was therefore calculated from MLW/MHW values in the permanent piezometers in these areas, since these were the only data available. The MG after the update was set equal to that for the method in the test area, since the sampling design was defined to this purpose (cf. Section 2.2.2). Results (Table 6) show, that the piezometer methods have the best (lowest) marginal cost, but this is a result of the low cost, and not of the accuracy of the update. Of the other methods, SRS-E has in general the most favourable marginal cost in the three areas, though SRS-S is quite comparable.

\subsection{Validation}

The cost of the updating in the Drenthe project based on 246 sample locations were $54 \mathrm{kEuro}$, which is slightly more than estimated (46 kEuro). The accuracy of the map resulting from the updating was not as good as predicted (MG of 0.32 instead of 0.12), and thus the marginal cost were somewhat less favourable as well.

\section{Discussion}

\subsection{Quality of update methods}

From Table 4 follows, that all methods result in less heterogeneous maps than the original map. In all cases, more than $40 \%$ of the GWT map units do not reoccur on the updated maps. This is partly due to historical facts such as increased artificial drainage, which causes the "wet" GWT to disappear. Partly, however, it may also be due to the updating methods (e.g., because some update methods cannot update GWT associations), but this could only be quantified when the area would be re mapped using traditional approaches, which is costly and beyond the scope of this project.

\subsection{Validation}

The somewhat poorer accuracy in the 75,684-ha area in the Province of Drenthe probably results from the assumption that the variograms for MLW and for MHW in the 9228-ha test area can be applied to all regions to estimate sample size. Probably, variability of MLW and MHW is higher in Drenthe than was foreseen because of the occurrence of boulder clay with highly variable starting depth and thickness, which strongly influences the spatial and temporal dynamics of phreatic water levels. Nevertheless, the validation results do not 
invalidate the statement that method SRS-E is suitable for GWT map updates in larger areas, since actual and predicted marginal cost are quite similar when compared to the values for the other methods.

\subsection{Potential of ancillary information: elevation data}

Ancillary information that is correlated to both MLW and MHW, can be used to reduce the number of samples or to improve the accuracy of the maps. If the
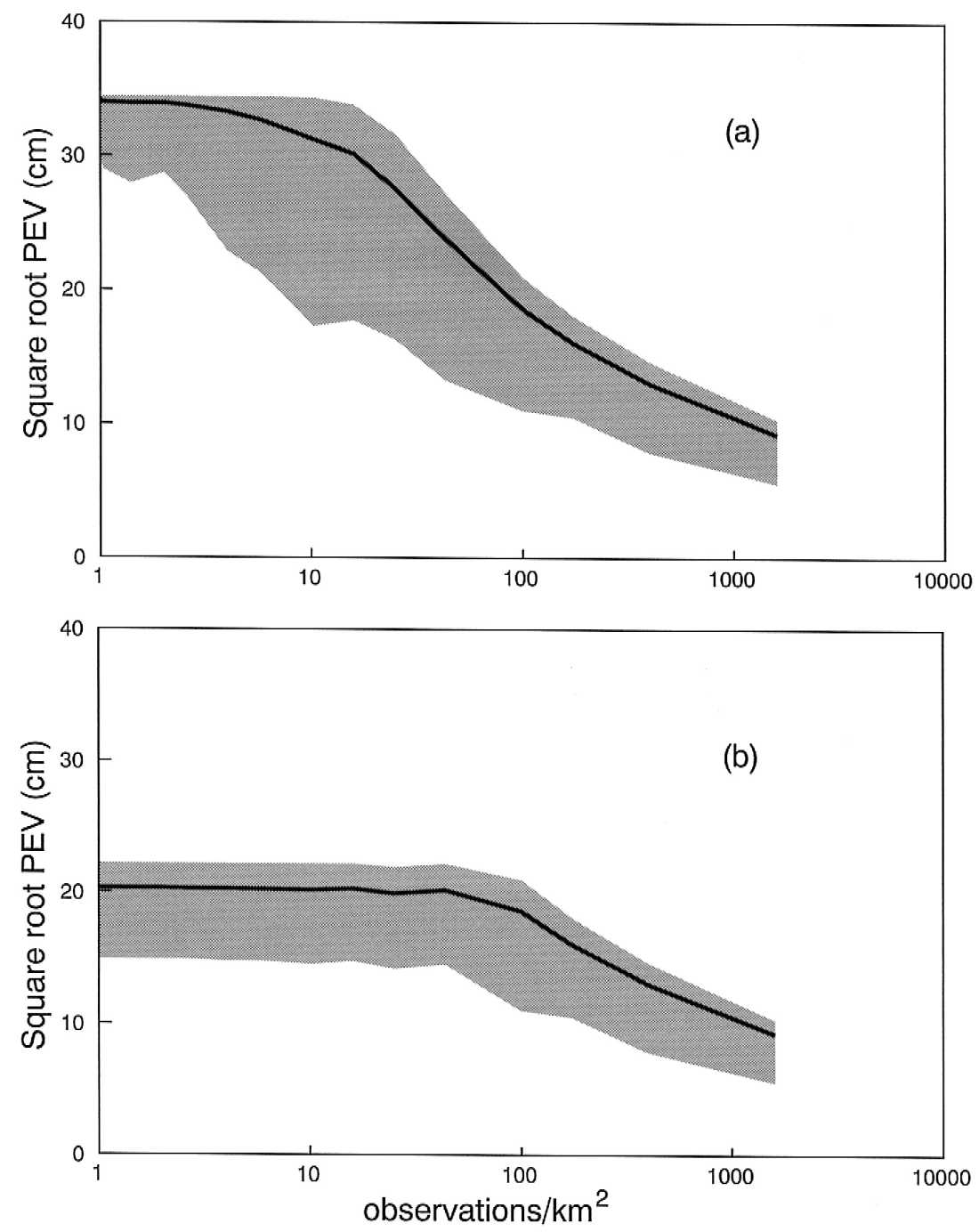

Fig. 6. Square root of average prediction error variance and the $95 \%$ distribution width as a function of sampling density for simple random sampling with (a) no ancillary data, and (b) 1 elevation point per hectare. 
spatial density of these data is high and if it proves a good predictor of MLW and MHW, updating the GWT map by redrawing polygons may be possible without much additional fieldwork. Elevation data have this potential (Te Riele et al., 1995), but up to date no national coverage of recent elevation data exists. As such, the potential use of elevation data can only be illustrated by analysing the cost development as a function of sampling density. Te Riele et al. (1995) found in an area, which is more or less comparable to the 9228-ha test area, a strong regression between elevation-derived data and the phreatic head at time $t$ $\left(h_{t}\right)$. The residual variance of this model was found to be $253.2 \mathrm{~cm}^{2}$. Application of kriging combined with regression (Knotters et al., 1995) allows the evaluation of the $\mathrm{R} \overline{\mathrm{PEV}}$ as a function of sampling density and at different densities of the ancillary information. Fig. 6 shows that the R $\overline{P E V}$ strongly responds to the use of these ancillary data, and that either interpolation accuracy will increase or sampling cost will decrease when elevation data become available and are used in the context of kriging. If the spatial density of the elevation data is high enough, then MLW and MHW information underlying GWT maps can be directly updated using regression-based techniques.

\section{Conclusions}

(1) GWT map updating methods based on stratified random sampling result in maps with high accuracy (low $M G$ ) at reasonable cost for areas of different size.

(2) Updating methods based on data from an existing network of piezometers are cheap but result in poor accuracy (high $M G$ ) and incomplete maps.

(3) An updating method based on kriging results in fairly good maps, but the cost related to sampling are high.

(4) High-resolution elevation data are known to be strongly correlated with phreatic heads, and therefore will provide useful ancillary information in GWT updating methods in the near future. Advances will either be a decrease in necessary sampling efforts and associated cost or an increase of map accuracy. Potentially, this will allow for GWT map updates by redrawing polygons, which is not yet possible at reasonable cost.

\section{References}

Beckett, P.H.T., Webster, R., 1971. Soil variability: a review. Soils Fert. 34, 1-15.

Bie, S.W., Beckett, P.H.T., 1971. Quality control in soil survey: II. The cost of soil survey. J. Soil Sci. 22 (4), 453-465.

Boers, P.C.M., Boogaard, H.L., Hoogeveen, J., 1997. Huidige en toekomstige belasting van het oppervlaktewater met stikstof en fosfaat vanuit de landbouw: uitspoeling meststoffen uit landbouw. [Current and future loadings to surface waters with $\mathrm{N}$ and $\mathrm{P}$ from agriculture: leaching of nutrients from agriculture], RIZA, 1997, 217 pp., ISBN 90-369-5061-9. 
Braat, L.C., van Amstel, A.R., Gerritsen, A.C., van Gool, C.R., Gremmen, N., Groen, C.L.G., Rolf, H.L.M., Runhaar, J., Wiertz, J., 1989. Verdroging van natuur en landschap in Nederland - beschrijving en analyse. [Man-induced drought of nature and landscape in the Netherlands

- description and analysis], Ministerie van Verkeer en Waterstaat, 's-Gravenhage.

Bregt, A.K., Stoorvogel, J.J., Bouma, J., Stein, A., 1992a. Mapping ordinal data in a soil survey: a Costa Rican example. Soil Sci. Am. J. 56, 525-531.

Bregt, A.K., Janssen, J.A.M., van de Griendt, J.S., Andriessen, W., Alkasuma, 1992b. Optimum observation density for mapping acid sulphate soils in Conoco, Indonesia: accuracy and costs. In: Bregt, A.K. (Ed.), Processing of soil survey data. PhD. Thesis, Wageningen.

Brus, D.J., 1994. Improving design-based estimation of spatial means by soil map stratification, a case study of phosphate saturation. Geoderma 62, 233-246.

Dent, D., Young, A., 1981. Soil Survey and Land Evaluation. George Allen and Unwin, London.

Domburg, P., de Gruijter, J.J., Brus, D.J., 1994. A structured approach to designing soil survey schemes with prediction of sampling error from variograms. Geoderma 62, 151-164.

Dumanski, J., Pettapiece, W.W., Acton, D.F., Claude, P.P., 1993. Application of agro-ecological concepts and hierarchy theory in the design of databases for spatial and temporal characterisation of land and soil. Geoderma 60, 343-358.

Finke, P.A., Wösten, J.H.M., Kroes, J.G., 1996. Comparison of two approaches to characterise soil map unit behavior in solute transport studies. Soil Sci. Soc. Am. J. 60, 200-205.

Haans, J.C.F.M., Steur, G.G.L., Heide, G. (Eds.), Progress in Land evaluation. Balkema, Rotterdam, 309 pp.

Kafritsas, J., Bras, R.L., 1981. The Practice of Kriging. Cambridge, Ralph M. Parsons Laboratory, Massachusetts Institute of Technology. Technical report 263.

Kitanidis, P.K., 1983. Statistical estimation of polynomial generalized covariance functions and hydrological applications. Water Resour. Res. 19 (4), 909-921.

Knotters, M., Brus, D.J., Oude Voshaar, J.H., 1995. A comparison of kriging, co-kriging and kriging combined with regression for spatial interpolation of horizon depth with censored data. Geoderma 67, 227-246.

Stolp, J., Knotters, M., Pleijter, G., 1994. Geostatistische interpolatie van de gemiddeld laagste grondwaterstand met behulp van hoogtepunten in een deel van het ruilverkavelingsgebied Aardenburg (Geostatistical interpolation of the mean lowest watertable using elevation measurements, in Dutch). Rapport 233, DLO-Staring Centrum, Wageningen.

Te Riele, W.J.M., Brus, D.J., 1991. Methoden van gerichte grondwaterstandmetingen voor het schatten van de GHG (Methods to estimate MHW from phreatic head measurements, in Dutch). Rapport 158, DLO-Staring Centrum, Wageningen.

Te Riele, W.J.M., Querner, E.P., Knotters, M., Pomper, A.B., 1995. Geostatistische interpolatie van grondwaterstandsdiepten met behulp van fysisch-geografische informatie en de resultaten van een regionaal stromingsmodel (Geostatistical interpolation of phreatic heads using morphometric information and a regional hydrological model, in Dutch). Rapport 414. DLO-Staring Centrum, Wageningen. 